\title{
Association of Forest-Origin Tree Species on the Development of Brown Root Disease in Sri Lankan Rubber Plantations
}

\author{
Silva M.K.R. ${ }^{1 *}$, Wijesundara R.L.C. ${ }^{2}$, Fernando T.H.P.S. ${ }^{1}$, Tennakoon B.I. ${ }^{1}$ and \\ Wijekoon W.M.S.P. ${ }^{1}$ \\ ${ }^{1}$ Rubber Research Institute of Sri Lanka \\ ${ }^{2}$ University of Colombo, Sri Lanka \\ *keshanisilva@yahoo.com
}

\begin{abstract}
Brown root disease caused by Phellinus noxius is widely distributed in tropical and sub-tropical regions in Asia and becoming an important root affecting fungi in Sri Lankan rubber plantations. Most of the economically-important plantation and other crop species as well as forestry species have been reported to be affected by this disease. However, the significance of the brown root rot was recognized only recently in Sri Lanka with the expansion of rubber to non-traditional areas in Uva, Northern and Eastern provinces and with low adoption of the recommended land preparation measures. According to the literature, this disease is usually found in many plantations where crop established on cleared forest sites. The objectives of the current study was to investigate the local host species of the disease and to evaluate the role of those species in the development of brown root disease in rubber. Seventy brown root disease incidences were used to assess the host range and the disease transmitting pattern. A structured questionnaire was used to collect the background information. In association with the roots of the diseased tuber trees, decayed roots of twenty species of forestry origin which were kept in situ were identified, exhibiting the similar signs and symptoms of the disease. However, the pathogen isolates could be isolated from only five alternative species, as some of the roots were too decayed. They were Cereya arboria (kahata), Ginelina arboria (eth demata), Bridelia retusa (keta kela), Mangifera indica (mango) and Artocarpus heterophillus (jak). These isolates showed a variation in their morphological and physiological characteristics. The studies on the pathogenicity and the cross infection ability are in progress. It was observed that in all disease incidences, the initially diseased rubber tree had a root contact with a diseased roots of some other species. Moreover, at all the incidences, land had been previously either under the forest or abandoned for years with trees and shrubs of forest origin. Based on these facts, it can be concluded that the infection of brown root disease to rubber has a correlation with the presence of other tree species in the root contact. It can therefore be expected that the innoculum is present in native forests on infected roots or woody debris and rubber plants got infected when the roots made contact with the infected roots and other woody debris of cleared native forests.
\end{abstract}

Keywords: Brown root disease, Rubber, Forest species

Proceedings of the International Forestry and Environment Symposium 2016, Department of Forestry and Environmental Science, University of Sri Jayewardenepura, Sri Lanka. 